thetic infusion through nerve sheath catheters for analgesia following upper extremity amputation. Clinical report. Reg Anesth 1997; 22: 351-6.

\section{A longer pretreatment interval does not improve cisatracurium precu- rarization}

To the Editor:

One report in the literature assessed the value of cisatracurium as a precurarizing agent and, in this report, $0.01 \mathrm{mg} \cdot \mathrm{kg}^{-1}$ cisatracurium given three minutes prior to succinylcholine $1.5 \mathrm{mg} \cdot \mathrm{kg}^{-1}$ was almost ineffective in preventing succinylcholine-induced fasciculations. ${ }^{1}$ We hypothesized that the time interval between cisatracurium and succinylcholine was too short and a longer pretreatment interval, i.e., six minutes rather than three minutes should improve the effectiveness of cisatracurium as a precurarizing agent. Therefore, we assessed the efficacy and the side effects of the same dose of cisatracurium, i.e., $0.01 \mathrm{mg} \cdot \mathrm{kg}^{-1}$ given six minutes prior to succinylcholine and compared them with a control group receiving placebo, i.e., $\mathrm{NaCl} 0.9 \%$ six minutes prior to succinylcholine $(n$ $=15$ for each group). In all patients anesthesia was induced with fentanyl $\left(1-2 \mu \mathrm{g} \cdot \mathrm{kg}^{-1}\right)$ and thiopentone (4-7 $\mathrm{mg} \cdot \mathrm{kg}^{-1}$ ) and maintained with remifentanil 0.25 $\mu \mathrm{g} \cdot \mathrm{kg}^{-1} \cdot \mathrm{min}^{-1}$ and desflurane $2-3 \%$ end-tidal in oxygen/air. Exactly five minutes after the injection of the precurarizing dose of cisatracurium or placebo all patients were asked for signs of muscle weakness, i.e., diplopia, heavy eyelids, dysarthria, difficulty in swallowing and dyspnea. The severity of muscle weakness

TABLE Muscle weakness after a precurarizing dose of 0.01 $\mathrm{mg} \cdot \mathrm{kg}^{-1}$ cisatracurium

\begin{tabular}{lll}
\hline & $\begin{array}{l}\text { Cisatracurium } \\
0.01 \mathrm{mg}^{-1} \mathrm{~kg}^{-1} \\
n=15\end{array}$ & $\begin{array}{l}\text { Placebo } \\
(\mathrm{NaCl} \mathrm{0.9 \% )} \\
n=15\end{array}$ \\
\hline $\begin{array}{ll}\text { Incidence } \\
\text { Symptoms }\end{array}$ & 13 & $3^{*}$ \\
$\quad$-heavy eyelids & 12 & \\
$\quad$-diplopia & 4 & 3 \\
$\quad$-dysarthria & 3 & 1 \\
$\quad$-dyspnea & 2 & 0 \\
$\quad$-swallowing difficulty & 3 & 0 \\
Severity & & 0 \\
$\quad$-one symptom & 9 & \\
$\quad$-two symptoms & 3 & 2 \\
$\quad$-three or more symptoms & 3 & 1 \\
\hline
\end{tabular}

Incidence of side effects $=$ number of patients; severity of side effects $=$ number of paralytic symptoms. ${ }^{*} P<0.05$. was defined as the number of symptoms (zero to five) mentioned by patients during this interview. Fasciculations after the injection of succinylcholine were recorded according to a four-point rating scale. ${ }^{2}$ Moreover, the incidence and the severity of myalgia were assessed $24 \mathrm{hr}$ after surgery with a standardized questionnaire. ${ }^{3}$ Compared to pretreatment with placebo, precurarization with $0.01 \mathrm{mg} \cdot \mathrm{kg}^{-1}$ cisatracurium six minutes prior to succinylcholine led to a significant reduction of fasciculations ( $87 \%$ vs $40 \%$, respectively; $P$ $<0.05$ ) but no reduction of myalgia ( $33 \%$ vs $20 \%$, respectively; NS). Moreover, this technique was associated with signs of muscle weakness in almost all patients (Table). Thus, cisatracurium $0.01 \mathrm{mg} \cdot \mathrm{kg}^{-1}$ given six minutes prior to succinylcholine was not only ineffective in preventing myalgia in a clinical contextthe expected reduction of myalgias is the most important reason for pretreating patients exposed to succinylcholine - it was also "highly effective" in producing side effects, i.e., signs of muscle weakness. These side effects may be harmful to patients, leading to pulmonary aspiration of gastric contents prior to intubation or producing significant alterations of pulmonary function..$^{4,5}$ In light of our results, we see no convincing evidence supporting the use of cisatracurium as a precurarizing agent.

Thomas Mencke MD

Christine Becker MD

Jan Uwe Schreiber MD

Thomas Fuchs-Buder MD

Saarland, Germany

\section{References}

1 Joshi GP, Hailey A, Cross S, Thompson-Bell G, Whitten $C C$. Effects of pretreatment with cisatracurium, rocuronium, and d-tubocurarine on succinylcholineinduced fasciculations and myalgia: a comparison with placebo. J Clin Anesth 1999; 11: 641-5.

2 Mingus ML, Herlich A, Eisenkraft JB. Attenuation of suxamethonium myalgias. Effect of midazolam and vecuronium. Anesthesia 1990; 45: 834-7.

3 Mencke T, Schreiber JU, Becker C, Bolte M, Fuchs-Buder $T$. Pretreatment before succinylcholine for outpatient anesthesia? Anesth Analg 2002; 94: 488-92.

4 Musich J, Walts LF. Pulmonary aspiration after a priming dose of vecuronium. Anesthesiology 1986; 64: 517-9.

5 Kopman AF, Khan NA, Neuman GG. Precurarization and priming: a theoretical analysis of safety and timing. Anesth Analg 2001; 93: 1253-63. 